\title{
Progress in studies of fish reproductive development regulation
}

\author{
CHEN Ji, HU Wei* \& ZHU ZuoYan \\ State Key Laboratory of Freshwater Ecology and Biotechnology, Institute of Hydrobiology, Chinese Academy of Sciences, Wuhan 430072, China
}

Received June 19, 2012; accepted September 28, 2012; published online November 23, 2012

\begin{abstract}
Mechanisms of the animal reproductive development are an important research field in life sciences. The study of the reproductive development and regulatory mechanisms in fishes is important for elucidating the mechanisms of animal reproduction. This paper summarizes recent advances in the mechanisms of fish sex determination and differentiation, of fish gonad development and maturation, and of fish germ cell development, as well as the according regulating strategies. Fishes comprise an evolutionary stage that links invertebrates and higher vertebrates. They include diversiform species, and almost all vertebrate types of reproduction have been found in fishes. All these will lead to important advances in the regulatory mechanisms of animal reproduction by using fishes as model organisms. It will also enable novel fish breeding techniques when new controllable on-off strategies of reproduction and/or sex in fishes have been developed.
\end{abstract}

fish, reproduction, regulation

Citation: Chen J, Hu W, Zhu Z Y. Progress in studies of fish reproductive development regulation. Chin Sci Bull, 2013, 58: 7-16, doi: 10.1007/s11434-012-5577-1

As low vertebrates, fishes are on an evolutionary stage linking invertebrates and higher vertebrates. There are as many as 28000 known fish species, which show large diversity. A range of sexual characteristics and reproductive strategies has been described for fishes, and almost all reproductive types of vertebrates have been found in fishes. The study of fish reproductive development regulation is important for elucidating mechanisms of animal reproductive development. Molecular breeding will reveal finer varieties when genes and regulatory networks associated with economically important traits (such as fast growth, disease resistance, cold tolerance and hypoxia tolerance) in fishes are discovered [1]. Reproduction also provides a precondition for culturing exclusive fish breeds and expanding fish populations. Breeding techniques such as sexual control and fertility control have played important roles in developing new fish varieties. This paper will review advances of fish reproductive development regulation, with the aim of providing hints for mechanisms of fish reproductive development, as well as providing theoretical guidance for tech-

*Corresponding author (email: huwei@ihb.ac.cn) niques of reproductive regulation and developing highyielding, efficient, eco-friendly breeds.

\section{Sexual control of fishes}

\subsection{Factors influencing sex determination}

The sex differentiation pattern and determination mechanism of fishes are very diverse. Various sexual phenotypes are all present in fishes, such as hermaphroditism, unisexuality, gonochorism and dual reproduction mode including parthenogenesis and sexual reproduction [2]. For those fishes in which sex chromosome systems exist, there are single chromosome systems, such as XX/XY, ZZ/ZW, XX/ $\mathrm{XO}$ and $\mathrm{ZZ} / \mathrm{ZO}$, and multiple chromosome systems, such as $\mathrm{XX} / \mathrm{XY}_{1} \mathrm{Y}_{2}, \mathrm{ZZ} / \mathrm{ZW}_{1} \mathrm{~W}_{2}, \mathrm{X}_{1} \mathrm{X}_{2} \mathrm{X}_{1} \mathrm{X}_{2} / \mathrm{X}_{1} \mathrm{X}_{2} \mathrm{Y}$, and $\mathrm{X}_{1} \mathrm{X}_{2} \mathrm{X}_{1} \mathrm{X}_{2} /$ $\mathrm{X}_{1} \mathrm{X}_{2} \mathrm{X}_{1}$. Like other animals, fish sex differentiation is controlled by their genetic system. However, fishes are oviparous, and their embryonic development proceeds in exposure to temperature-variable water. Thus, their external physical environment inevitably affects sex differentiation of fishes. 


\subsubsection{Genetic sex determination}

In vertebrates, it appears that genes involved in sex determination and differentiation have the tendency to move onto the heteromorphic sex chromosomes, which may be a common feature of these genes [3,4]. Thus, when it comes to the study of fish sex determination mechanisms, a strategy of searching sex chromosomes for sex determination genes was always preferred. Based on the statistical data given by Arkhipchuk, among more than 1700 fish species that had been cytogenetically characterized until 1995, approximately 176 species had been found to have cytogenetically distinct sex chromosomes [5], which present important material for exploring mechanisms of fish sex determination. The guppy (Poecilia reticulata) has cytogenetically differentiated sex chromosomes. In the early pachytene stage, a segment on the $\mathrm{Y}$ chromosome is unpaired with the $\mathrm{X}$ chromosome. Comparative genomic hybridization $(\mathrm{CGH})$ differentiated a large block of predominantly male-specific repetitive DNA in the region [6]. Artieri et al. [7] identified chromosome 2 of the Atlantic salmon (Salmo salar) as the sex chromosome by using probes designed from the flanking regions of sex-linked microsatellite markers. The region containing the sex-determining locus appeared to locate between the Ssa202DU marker and a region of heterochromatin on the long arm. They then used an in silico approach to draw a physical map of chromosome 2 with a view to sequencing and identifying the sexdetermining gene. The $\mathrm{X}$ chromosome of the spiny eel (Mastacembelus aculeatus) was microdissected by Zhao et al. [8]. They constructed an X chromosome library and isolated a repetitive sequence. The repetitive sequence was found by fluorescence in situ hybridization (FISH) to distribute on regions of the $\mathrm{X}$ chromosome different from the $\mathrm{Y}$ chromosome. Despite the studies described above, it is difficult to isolate sex-determining genes on heteromorphic sex chromosomes due to their heterochromatin containing large regions of repetitive sequences. How to locate sex-determining loci on sex chromosomes of fishes and how to discriminate sex-determining associated genes from large numbers of repetitive sequences is crucial for studying mechanisms of sex determination by using fish sex chromosomes.

Comparing sex determination-associated genes of other species with homologs of fishes is another strategy of searching for sex-determining genes of fishes. However, homologs of wt1, sf-1, amh and daxl, which play roles in mammalian sex determination, were found to only have indirect regulatory effects on sex differentiating signal pathways in fishes [9-12].

The ffld gene of zebrafish (Danio rerio), a homolog of the mammalian $s f-1$ gene, is expressed in the hypothalamus and gonads, especially in testicular Sertoli cells and Leydig cells, and can regulate the expression of amh [10]. In zebrafish testes, amh is expressed in presumptive Sertoli cells, which may be regulated by SF-1, GATA and WT1, and is related to the proliferation and differentiation of spermatogonia [13]. The cyp19 gene encodes aromatase, the enzyme that converts androgens to estrogens. Fish cyp 19al participates in ovary development, and cyp19a2 is indirectly involved in sexual differentiation via the hypothalamus-pituitary-gonad axis (HPG axis) [14]. The expression patterns of cyp19ala and cyp19alb of 3-month-old and 10-month-old common carp (Cyprinus carpio) were investigated in our laboratory. Important roles of $s f-1$ and cyp19alb in testis development and of cyp19ala in ovary development were suggested [15]. Guiguen et al. [16] hypothesized that upregulation of cyp19ala is required for triggering and maintaining ovarian differentiation, and that cyp 19ala downregulation was necessary for inducing a testicular differentiation pathway. Furthermore, SF-1, FOXL2 and AMH are believed to regulate expression of cyp19al [17], which again suggests the indirect effect of those factors in fish sex determination.

Members of the SOX gene family are highly conserved in vertebrates and regulate extensive development pathways. However, the homologs of SOX in fishes are not crucial for sex determination. Sexually dimorphic expression modes of sox9 have been reported for some fish species [18]. Although it plays a role in testis organogenesis, no evidence was found which could demonstrate that sox 9 directs sex determination.

Many members of the DMRT gene family are surmised to be involved in sex determination. The dmrtl gene is thought to be a primary sex-determining gene in vertebrates. In fishes, its expression was only found in gonads. Furthermore, it showed higher expression in testes than in ovaries for some species, and it might be related to the formation and maintenance of the testes. The ontogenetic expression pattern of dmrtl in Gobiocypris rarus was analyzed using semi-quantitative PCR in our laboratory, and the results showed a higher expression in testes than in ovaries since five days after hatching [19].

The DMY gene of medaka (Oryzias latipes), a functional copy of dmrtl on the $\mathrm{Y}$ chromosome, is a sex-determining gene with the solidest evidence to be responsible for formation and differentiation of the testes [20,21]. However, phylogenetic analysis indicated that the duplication of dmrtl occurred after medaka evolved from other Oryziatidae species, which means that DMY does not exist in other fish species.

Recently, a duplicated gene of amh on Y chromosome of Odontesthes hatcheri, named amhy, was isolated by Hattori et al. [22]. The results from spatio-temporal expression analysis and gene knockdown suggested that amhy may play a critical role in the sex determination in this species. Compared with sry, dmrtl and DMY, which encode transcription factors to determine sex in some species, amhy may be a unique case of a hormone-related gene mastering sex determination in vertebrates.

Li et al. [23] identified sex chromosomes of Salmo trutta, S. salar and Oncorhynchus mykiss by FISH. The sex chro- 
mosomes showed different origins and the sex-determining genes might differ in these three salmonid species. Vandeputte et al. [24] proposed a polygenic hypothesis for sex determination in the European sea bass (Dicentrarchus labrax). Bradley et al. [25] reported a genome-wide linkage study of sex determination in zebrafish using a SNP genetic map. They confirmed two loci on chromosomes 5 and 16, respectively, containing sex-determining related genes, which turned out to be dmrt1 and cyp21a2. However, mutations of the two loci only accounted for about $16 \%$ of variance of the trait. Liew et al. [26] found that zebrafish sex was mainly determined genetically using repeated single pair crossings. Furthermore, using a FluoMEP assay or array comparative genomic hybridization, they failed to find universal sex-linked differences between the male and female genomes. They therefore proposed that zebrafish have a polygenic sex determination system.

Based on the studies described above, it appears that most fish species do not possess functionally specialized sex-determining genes. It is believed that fish sex may be determined by polygenic systems, which are influenced by the environment and other factors. This could explain why varieties of molecular mechanisms of sex determination are found in fishes.

\subsubsection{Environmental sex determination}

The sex differentiation of fishes is influenced by environmental factors, such as temperature, exogenous hormones and behavior control [27].

Among the environmental factors, temperature has a stronger influence on sex differentiation. Menidia menidia was the first reported fish species in which both temperature and genes played a role in sex differentiation during the mid-larval stage [28]. Further studies demonstrated that both genetic and environmental factors have effects on sex differentiation in fishes. In some extreme cases, temperature factor can even rise above genetic determination to induce sex change. At high temperatures $\left(32-34^{\circ} \mathrm{C}\right)$, the level of cortisol in the entire body of medaka is elevated. This change inhibits female-type proliferation of germ cells as well as expression of follicle-stimulating hormone (FSH) receptor mRNA, which gives rise to masculinization of $\mathrm{XX}$ medaka [29]. It appears that the response to temperature depends on the fish species. In general, for most temperature-sensitive species, the ratio of males to females is increased at higher temperatures [30]. However, species such as Gambusia affinis and Coregonus hoyi are entirely temperature-independent [31]. Yamaguchi et al. [32] studied molecular mechanisms of temperature-dependent sex determination in the Japanese flounder, Paralichthys olivaceus. They found that high temperature treatment inhibited expression of foxl2 and FSH receptor, and surmised that the transcription of cyp19al was suppressed indirectly by high temperature, which led to the masculinization of $P$. olivaceus.

The view that fish sex differentiation can be induced by exogenous sex steroids is widely accepted. In most cases, short time treatment with sex steroids at early stages of sex determination (embryonic development stage) can permanently change and maintain fish phenotypic sex. Sometimes, persistent administration of sex steroids could result in hypoplastic gonads or sterility [33]. In another case, male chinook salmon, Oncorhynchus tshawytscha, could be induced to become females with the androgen 17-MT(17 $\alpha$-methyltestosterone) [34]. This phenomenon has been interpreted as the result of the estrogen receptor recognizing aromatized 17-MT.

With regards to use of the term "estrogens", it should be pointed out that it commonly refers to the hormones possessed only by females, a view challenged by recent studies. Ito et al. [35] found two kinds of estrogen receptors in Sertoli cells and even in haploid germ cells of the Japanese common goby, Acanthogobius flavimanus, suggesting that estrogens might play a role in regulating male germ cells development. Chaves-Pozo et al. [36] treated gilthead seabream, Sparus aurata L., with high doses of $17 \beta$-estradiol (E2). They found that E2 could inhibit the proliferation of spermatogonia, induce the apoptosis of primary spermatogonia and accelerate spermatogenesis. Another study by Miura et al. [37] indicated the role of a kind of progestin (17- $\alpha$-20- $\beta$-dihydroxy-4-pregnen-3-one, DHP) in initiating meiosis of eel spermatogenetic cells. These findings strongly suggest a role of estrogens in fish testes development and maturation. On the other hand, a report by Liu et al. [38], in which androgen receptors were found in ovary tissue of Spinibarbus denticulatus, suggested a role of androgens in ovary development. Taken together, it appears that a collaboration of estrogens and androgens regulate fish reproductive development, and that a balanced coordination of two classes of sex steroids determine sex differentiation.

In some fish species, social factors also have an effect on sex determination. In one group some individuals can influence other individuals by their behavior. The population usually consists of a group of smaller individuals of a common sex and fewer larger dominant individuals of the opposite sex. When the dominant individual leaves or cannot control the other individuals, the second dominant individual will change its sex and replace the former [39].

\subsection{Sex reversal in fishes}

Some fish species reverse their sex naturally at some developmental stage. Fishes such as Epinephelus sp., Pagrus major and Monopterus albus, have to undergo sex reversal during their ontogenesis. The molecular mechanism of sex reversal is a classical and interesting research topic in fish reproductive development biology. Bhandari et al. [40] showed that the body size of hermaphrodites correlated with age and sex, which led them to always remain in the sex with higher fertility. The dmrtl and SOX gene families might play important roles in sex change from female to 
male. The cDNA libraries of hypothalamus, pituitary and gonad tissue in several developmental stages of male orange-spotted groupers (Epinephelus coioides) were constructed by Zhou et al. [41]. They identified more than 10 genes involved in sex reversal of the grouper, including dmrtl involved in spermatogonia differentiating into spermatocytes, and sox3 involved in oogenesis regulation. The mRNA expressions of dmrtl and foxl2 during female to male change of honeycomb groupers (Epinephelus merra) were analyzed by Alam et al. [42]. The results suggested that the down-regulation of foxl2 accelerated oocyte degeneration, while the up-regulation of $d m r t 1$ led to the differentiation of germ cells into spermatogonia and promoted sex reversal. Huang et al. [43] found multiple alternative splicing of dmrtl in gonad transformation of rice field eel, $M$. albus, two transcripts of which showed increased expression during female to male change. The mRNA expression pattern of sox 9 during artificial sex reversal of orange-spotted groupers was analyzed by our group, and we hypothesized that $\operatorname{sox} 9$ was an important factor to initiate and maintain masculinization [44]. In conclusion, fishes that naturally reverse their sex present a unique experimental opportunity for studying mechanisms of animal sex determination and differentiation.

Sex steroids are involved in the development and maintenance of gonads. The levels of varieties of sex steroids fluctuate during sex reversal. Kokokiris et al. [45] found during the sex change from female to male of protogynous Mediterranean red porgy (Pagrus pagrus) that androgen (11-ketotestosterone and testosterone, 11-KT and $\mathrm{T})$ levels in serum rose and estrogen (estrone and $17 \beta$ estradiol, E1 and E2) levels dropped. On the other hand, when protandrous black porgy (Acanthopagrus schlegeli) underwent sex change from male to female, the E2 levels increased [46]. It is obvious that sex steroids have an important role in fish sex reversal. The effect of sex steroids on sex differentiation of fishes was further confirmed by experiments of immersing or feeding fish with sex steroids. Li et al. [47] implanted MT, MDHT(non-aromatizable 17 $\alpha$ methydihydrotestosterone) and MT+AI (aromatase inhibitor) into the body of red-spotted groupers (Epinephelus akaara), respectively. One month later, they obtained groupers with intersex gonads containing aretic oocytes and spermatogenic cells in several developmental stages, whereas male $\mathrm{Ha}$ lichoeres trimaculatus turned into females after 12 weeks of feeding with E2 [48]. Bhandari et al. [49] treated female honeycomb groupers (Epinephelus merra) with 11-KT by intraperitoneal injection, and the treated groupers were induced into $100 \%$ males after 75 days. Aromatase is encoded by cyp19ala. Treating red-spotted groupers with aromatase inhibitors also resulted in female-to-male sex change [50]. Guiguen et al. [16] proposed that cyp19ala and endogenous estrogens were crucial for natural sex reversal. Their reduced expression initiated female-to-male change and their elevation triggered male-to-female change.
Groupers and rice field eels are both economically important hermaphrodites, which produce eggs at first. In production, the late occurrence of natural sex reversal of grouper causes lack of male parents, whereas the early occurrence of sex change in rice field eel leads to smaller female parents with fewer numbers of eggs. In order to promote aquaculture of these two fish species, it will be important to establish a regulatory technology to control endogenous sex steroids levels, by which sex reversal of groupers can be brought forward or sex reversal of rice field eels can be postponed.

\subsection{Sex-controlled breeding}

Many fishes show sexual dimorphism in growth rate or age of sexual maturation. Before sexual maturation, the energy fishes take in is mainly used for body growth. In some species such as common carp, females show a faster growth rate, due to ovary maturation occurring later than testis maturation. In other species, such as Pelteobagrus fulvidraco and Tilapia nilotica, males show a faster growth rate. For fishes with a high reproductive capacity, such as tilapia, raising both sexes in one pool will produce plenty of offspring, which wastes resources. For these reasons, it is important for fish culture to produce all-males or allfemales by using sex-controlling technologies. All-female carp and all-male P. fulvidraco have been produced by using sex steroids and inducing gynogenesis [51,52].

Estrogens play an important role in fish sex differentiation, which are regarded as a natural inducer of ovary differentiation [11,53]. The amount of estrogens correlates closely to the expression levels of aromatases. Therefore, some researchers tried to control the level of estrogens by regulating aromatase expression to impact on sex differentiation to control sex.

Wang et al. [54] produced transgenic tilapia in which dmrtl was over-expressed to inhibit transcription of cyp19ala. The E2 level in serum of transgenic fish was lower, the ovarian cavity development was retarded, follicles degenerated to varying degrees, and even about $5 \%$ of all individuals developed into males. FOXL2 promotes synthesis of estrogens and development of ovary by upregulating cyp 19ala expression in female fish. A dominant negative mutant of foxl2 was transferred into female tilapia to interfere with the endogenous FOXL2 functions [17]. The expression of cyp19ala was suppressed, as well as reduction of serum estrogens level, and transgenic fishes resulted in masculinization. Rodriguez-Mari et al. [55] inserted Tol2 into the coding region of Fancl in zebrafish to inactivate it. They observed apoptosis of germ cells during sex differentiation, thus compromising oocyte survival, and lower expression of cyp19ala. The gonads became testes and the mutant fishes developed into males. Taken together, the goal of controlling sex can be achieved by regulating the expression of factors in signal pathways of sex differentia- 
tion, which is hoped to develop into a new technology.

Other investigations showed that knockdown of $d n d$, a gene involved in development and migration of primary germ cells (PGC), caused apoptosis of PGCs in zebrafish and medaka. The germ cell-ablated fish developed into males and had the ability of inducing females to lay eggs [56,57].

\section{Fish reproductive control}

There is a close relationship between growth and reproduction in fishes [58]. Rendering fishes sterile by manipulating reproduction will reduce the energy consumption distributed to reproduction, thus the fishes will grow faster. On the other hand, the ecological risks have become a bottleneck restriction to introducing foreign species and industrialization of transgenic fishes. Strategies of creating sterile fish would avoid the ecological risk entirely [59,60]. Reproductive control is important for a sustainable development of fish varieties and for updating and breeding studies of transgenic fishes.

\subsection{Development of fish gonads}

\subsubsection{Development of fish germ cells}

The reproductive development of fishes includes generation, migration, proliferation, and differentiation of PGCs and production of gametes [61]. vasa was the first verified gene specifically expressed in PGCs of fishes [62]. By marking germ cells with fluorescence using germ cell special promoters or 3'-UTR [63], the formation process of gonads could be tracked down. Combined with gene knock-down/-out, it is useful for exploring new regulatory factors of reproduction.

Whole mount in situ hybridization (WISH) of zebrafish embryos with probe designed from vasa showed four signals located on the marginal positions of the first cleavage plane at 2- or 4-cell stage [64]. During the cleavage stage until the $1 \mathrm{~K}$-cell stage, the number of vasa-positive cells remains four, with fixed locations in the embryo. The expression patterns of vasa in rare minnow (Gobiocypris rarus) were proved similar to those in zebrafish by our group [65]. In medaka, however, the vasa RNA was observed widely distributed in early embryos. It did not show a special distribution until the late gastrula stage with 10-25 vasa-positive cells concentrating on both sides of the posterior shield [66]. Two different expression patterns of vasa suggested a variety of occurrence patterns of germ cells.

In zebrafish, PGCs start to migrate since dome stage, accompanied by reduced synthesis of E-cadherin. Some genes are transcribed in PGCs, and the gene $d n d$, the product of which can combine with RNA, is essential for the transcription [67]. PGCs become polarized and the receptor CXCR4 on them can recognize the chemokine SDF1a, then PGCs are attracted to move towards SDF1a locations. The somatic cells in the path of migration and embryonic primordia express SDF1 one by one to introduce PGC to the destination
[68]. At the same time, the orderly expression of CXCR7 in somatic cells, another receptor of SDF1a, can eliminate redundant SDF1 to guide the migration [69].

The migration of medaka PGCs is guided by SDF1a and SDF1b [70], similar to zebrafish. Kunwar et al. [71] suggested a potentially universal rule that the migration direction of PGCs is decided by the balance of attractive and repellant cues, which is mediated by $\mathrm{G}$ protein-coupled receptors. Once PGCs arrive at their destination, some of them proliferate to maintain the number of stem germ cells, while others differentiate into spermatocytes or oocytes, then enter into meiosis, and finally produce gametes .

Until now, few factors associated with fish germ cells differentiation are known. Herpin et al. [72] observed that DMY could arrest germ cells of male medaka in the G2 phase. In situ hybridization in medaka showed that mis mRNA was expressed in the somatic cells surrounding germ cells during sex differentiation, and that MIS protein was thought to promote germ cells differentiation by acting on the somatic cells [73]. In zebrafish, PIWI could combine with germ cell specific piRNA, which is essential for germ cells maintenance and differentiation [74].

Factors involved in germ cell maturation include pituitary hormones, sex steroids and growth factors. Pituitary hormones include FSH (follicle stimulating hormone), LH (luteinizing hormone), GH (growth hormone) and so on. Sex steroids mainly include progestin, androgens and estrogens. Growth factors include activin, GSDF (gonad soma derived factor), AMH (anti-Mullerian hormone), IGF-1 (insulin-like growth factor I), etc. For detailed reviews, please see Schulz et al. [75] and Lubzens et al. [76].

\subsubsection{Endocrine regulation of fish gonad development}

The development and maturation of fish gonads are controlled by genetic and environmental factors, and regulated by a molecular network of signals. As in other vertebrates, the HPG axis of the neuroendocrine system plays a central regulatory role on the reproductive development of fishes. Gonadotropin-releasing hormone $(\mathrm{GnRH})$, lying upstream of the HPG axis, is a key regulatory factor. Once hypothalamus-secreted GnRH arrives at the pituitary gland, the cAMP signal pathway in gonadotrophs will be activated, transcription, synthesis and secreting of FSH and LH are all up-regulated. Via blood circulation, FSH and LH enter the gonads to regulate gonad development and to promote sexual maturation by stimulating production of sex steroids. On the other hand, sex steroids can inhibit synthesis of GnRH in the hypothalamus through a negative feedback pathway.

In recent years, the discoveries of kisspeptin, which can positively regulate $\mathrm{GnRH}$, and $\mathrm{GnIH}$, which can negatively regulate $\mathrm{GnRH}$, have been praised as two remarkable breakthroughs in vertebrate neuroendocrinology [77]. They have become attractive topics in fish reproduction and physiological research.

Kisspeptin is a neuropeptide encoded by the kiss gene, 
and with GPR54 as the receptor. The first research about kiss function was carried out in hypogonadism [78]. The patients had delayed pubertal maturation and reproductive function due to a mutation in the gene encoding GPR54. Subsequent studies in mice, rats and monkeys further confirmed the functions of kisspeptin and GPR54 in reproductive development. Currently, the roles kisspeptin is thought to play include: sexual differentiation of the brain, the initiation of puberty, secretion and release of $\mathrm{GnRH}$, transmission of feedback signals of sex steroids and control of reproductive function by a photoperiodic factor [79].

Currently, functional research of Kisspeptin and GPR54 in fish reproduction is developing rapidly. Parhar et al. [80] found mRNA of GPR54 in GnRH neurons of tilapia, which suggested a direct effect of kisspeptin on GnRH neurons. Kitahashi et al. [81] cloned and expressed the Kiss2 gene of zebrafish and medaka. Via intraperitoneal administration and real-time PCR, they observed a more important role of kiss 2 than kiss 1 in regulating zebrafish sex steroid synthesis. Li et al. [82] observed elevated levels of LH in goldfish serum after intraperitoneal administration of mature kisspeptin peptides. However, Pasquier et al. [83] confirmed an inhibitory effect of kisspeptin on LH levels of the eel, Anguilla anguilla. It is worth noting that two or three types of GnRH usually coexist in one fish species, and that two types of kisspeptin and GPR54, respectively, are also found. Thus, the relationship between the kisspeptin/GPR54 signal system and GnRH, as well as regulatory mechanisms on reproduction, might differ between fishes and mammals.

GnIH (gonadotropin-inhibitory hormone) was first found in birds by Japanese scientists in 2000. Subsequent studies showed that $\mathrm{GnIH}$ might regulate reproduction of birds and mammals on every level of the HPG axis. It can inhibit synthesis and release of LH and FSH, induce apoptosis of testis cells, and might have a regulatory effect on the production of sex steroids as well as on the differentiation and maturation of germ cells by the way of autocrine or paracrine mechanisms [84]. The functional study of $\mathrm{GnIH}$ in fishes has just started, and there are still many inconsistent findings. For instance, Zhang et al. [85] detected lower levels of LH in the serum of mature female goldfish after intraperitoneal administration of zebrafish $\mathrm{GnIH}$ peptides, which demonstrated that GnIH could negatively regulate release of LH in goldfish. On the contrary, the results from intraperitoneal administration of $\mathrm{GnIH}$ to goldfish at developmental stages from early to late gonad recrudescence showed that $\mathrm{GnIH}$ increased pituitary LH- $\beta$ and FSH- $\beta$ mRNA levels as well as reduced serum LH and pituitary GnIH-R mRNA levels [86]. It has been suggested that GnIH has a seasonal effect on LH and FSH. This could change our understanding of the regulation of fish reproductive axis. It would also help us to study the function of $\mathrm{GnIH}$ in fish reproduction and explore new factors negatively regulating $\mathrm{GnIH}$.

There are also types of molecules that can indirectly regulate fish reproductive development by affecting the HPG axis. For example, in many teleosts the release of GtH can be inhibited by dopamine (DA) [87], or be accelerated by $\gamma$-aminobutyric acid (GABA) [88], and secretion of GtH can be stimulated by neuropeptide Y (NPY) [85]. In our group, suppression subtractive hybridization (SSH) and cDNA microarray were applied to sterile females of the common carp with abnormal gonads and to wild type common carp [89]. We found more than 200 genes expressed differently at the hypothalamus, pituitary or gonad level, which included 87 unknown genes, whereas the other genes were associated with growth, organogenesis, energy metabolization, immune response, signal transduction and cell apoptosis. The results showed a very complex molecular network regulating fish reproductive development.

\subsection{Strategies of fish reproductive control}

Since GnRH is known as a key factor in HPG axis, many trials have been undertaken to control fish reproduction by suppressing GnRH expression [90,91]. In our group, endogenous sGnRH expression was suppressed by using the anti-sense transgenic method, which led to a genesis of gonads $[89,92]$. The result demonstrated that fish reproduction could be controlled by suppressing critical signal molecules associated with reproductive development.

The development of gonads can be seen as a process of generation, migration, proliferation, differentiation of PGCs as well as a production of gametes. Apoptosis of germ cells can be induced by interfering with the expression of genes associated with germ cell development. In zebrafish, knockdown of $d$ nd using Morpholino caused PGCs losing their migratory ability and resulted in apoptosis [93]. Suppression of nanos 1 inhibited PGCs from migrating properly and reduced their number [94]. PGCs would migrate abnormally and induce apoptosis when Stau was knocked down [95]. PGCs of a zili-deficient mutant also induced apoptosis before reaching meiosis [74].

Another strategy targeting germ cells to control reproduction of fishes is to kill germ cells directly and specifically. Slanchev and Stebler [56] expressed kid, a bacterial toxin, preferentially in PGCs and simultaneously expressed the antidote kis uniformly in zebrafish. They obtained normally developing embryos but abated PGCs. Hsu et al. [96] and $\mathrm{Hu}$ et al. [97] expressed the nitroreductase gene specifically in zebrafish gonads using $z p$, asp, odf or sam promoter. When transgenic zebrafish were immersed in metronidazole, the nitroreductase expressed in germ cells turned metronidazole into cytotoxins and the germ cells were killed. It should be noted that the technologies listed above involved cell apoptosis or cytotoxicity. The question remains how we can abate germ cells specifically and efficiently without affecting growth of somatic cells or expressing cytotoxic proteins. For reasons of food security, this is a problem that needs to be resolved before this strategy can be applied to fish breeding. 


\section{Cell engineering in fish reproductive tech- nology}

Cell engineering in fish reproductive technology includes the transplantation of germ cells and the induction of stem cells.

The transplantation technique of cell nuclei has been established in zebrafish and medaka [98-100]. Transplantation of sperm nuclei in medaka was established by Liu et al. [101], who immersed medaka sperms in a solution containing RFP-expressing plasmids and then transferred the sperm nuclei into unfertilized eggs. In the nuclear transplants, 50\% expressed RFP and about 5\% embryos developed into mature fish. This kind of germ cell nuclear transplant could be modified to be an efficient transgenic method. However, the survival rate of nuclei transplants is low, due to incomplete reprogramming of donor nuclei. Thus, this transplantation technique of cell nuclei needs to be improved. In our laboratory, we found that dome and shield stages were key stages in reprogramming zebrafish nuclei-transplanted cells. Proper expression of $m y c b$ and $k l f$ also determined whether transplants would develop successfully or not $[102,103]$.

The process of "borrow belly raw son" in fishes means transplanting PGCs of one fish species into the abdomen of another. The transplanted donor PGCs can develop independently or participate in gonad development, which can produce mature gametes of the donor fish. To find an efficient transgenic method, the technique of "borrow belly of fish" was established by Takeuch et al. [104], and has been constantly modified and improved since then. Saito et al. [105] killed germ cells of zebrafish at the blastula stage by first using dnd Morpholino and then transplanted a single PGC from a pearl danio (Danio albolineatus) into the zebrafish embryo. The transplanted cells migrated to gonad anlage, formed one side gonad and could produce functional gametes. Thereafter, Saito et al. [106] compared the efficiency of PGC transfer between the methods of transplanting a single PGC and transplanting blastomeres. They considered the mechanism of PGC migration to be highly conserved in fishes, and found that transplanting a single PGC was more efficient than transplanting blastomeres. Nobrega et al. [107] transplanted spermatogonial stem cells of zebrafish into male and female recipients. From the results of donor-derived spermatogenesis and oogenesis, they demonstrated that germ cell differentiation could be influenced by the environment. Successful transplantation of PGCs from Odontesthes bonariensis into the gonads of sexually mature O. hatcheri was conducted by Majhi et al. [108]. After six months, the transplanted cells resumed spermatogenesis, which means that germ cell transplantation could shorten the reproduction time of donor fishes. Reports that the "borrow belly of fish" technique had been carried out successfully between salmon and rainbow trout as well as two tilapia species [109,110], which are economically important fish, are very exciting. Such research indicates that "borrow belly of fish" between different fish species has become increasingly common. It has become valuable for shortening breeding cycles of economically important fish species and for the conservation of endangered fish species.

The technique of in vitro stem cell culture facilitates animal gene manipulation at the level of individuals. Few fish stem cell lines have been obtained so far. An embryonic stem cell line from medaka has been established, which is stable and can differentiate into a variety of cell types to form chimeras of medaka embryos [111,112]. Chen et al. [113] reported several embryonic stem cell lines from sea fishes with chimerical competence. An embryonic stem cell line from zebrafish could be maintained in vitro for a time, but then lost its pluripotency [114]. A striking report was published by Yi et al. [115], who established a haploid embryonic stem cell line which maintained characteristics of stem cells and could form embryonic chimeras with diploid cells. Its nuclei could even be transferred into normal eggs to produce fertile adult fishes. This study used a technique of semi-cloning of animals, demonstrating that haploid embryonic stem cell nuclei could initiate fertilization and produce offspring. This is regarded as a major breakthrough in reproductive biology.

Regarding germ line stem cells, attempts were concentrated on isolating and culturing spermatogonial cells. The first established fish spermatogonial cell line was derived from medaka, and could be induced to differentiate into functional sperm cells [116]. Sakai [117] described a method of isolating and culturing spermatogonial cells from zebrafish. Later, Fan et al. [118] isolated RFP-labeled zebrafish PGCs by flow cytometry and cultured them in vitro for more than four months. Shikina and Yoshizaki [119] used a similar approach to isolate spermatogonial cells from rainbow trout. Panda et al. [120] isolated and enriched spermatogonial cells from Labeo rohita and propagated them in vitro. No cases of culturing fish oogonia have been reported except a recent observation of germ line stem cells in medaka ovaries [121]. Techniques of culturing fish germ line stem cells in vitro and inducing them to differentiate in the correct orientation will provide new inspiration for fish breeding methods.

\section{Conclusions and perspectives}

There are about 28000 known fish species, which is more than all other vertebrate species. Fishes are on an evolutionary stage linking invertebrates and higher vertebrates. They also have varieties of sexual characteristics and reproductive strategies that are representative for all vertebrate species. It is expected that these features will lead to important advances in understanding the regulatory mechanisms of animal reproduction by using fishes as models.

An increasing number of studies suggest a complex network that regulates fish reproductive development. Genome sequencing of model fish species such as zebrafish and 
medaka as well as economically important species such as tilapia and grass carp will provide important information for isolating functional genes, exploring signal pathways and interpreting molecular networks that control or regulate fish reproduction.

Fish reproduction is a precondition for culturing specific fish breeds and increasing their populations. Many fish species with good economical traits are difficult to handle with artificial reproductive manipulation to become refined cultured strains. Establishing controllable on-off techniques of reproduction and sex would open new possibilities for fish breeding.

Manipulating fish reproduction is regulating the generation, maintenance and differentiation of germ cells, as well as the interaction between germ cells and somatic cells. Establishing controllable on-off techniques of reproduction and sex depends on various factors, including a thorough theoretical understanding of reproductive regulatory networks, of mechanisms of sex determination and differentiation, and of mechanisms of germ cell growth and development. Further required are improved techniques of manipulating fish genomes, regulating target gene expression consistently, and identifying genotypes and phenotypes accurately and efficiently.

This work was supported by National Natural Science Foundation of China (30930069), the Knowledge Innovation Project of the Chinese Academy of Sciences (KSCX2-EW-N-004), and the National High Technology Research and Development Program of China (2011AA100404).

1 Gui J F, Zhu Z Y. Molecular basis and genetic improvement of economically important traits in aquaculture animals. Chin Sci Bull, 2012, 57: 1751-1760

2 Gui J F, Zhou L. Genetic basis and breeding application of clonal diversity and dual reproduction modes in polyploidy Carassius auratus gibelio. Sci China Life Sci, 2010, 53: 409-415

3 van Doom G S, Kirkpatrick M. Turnover of sex chromosomes induced by sexual conflict. Nature, 2007, 449: 909-912

4 Ross J A, Urton J R, Boland J. Turnover of sex chromosomes in the stickleback fishes (gasterosteidae). PLoS Genet, 2009, 2: e1000391

5 Arkhipchuk V V. Role of chromosomal and genome mutations in the evolution of bony fishes. Hydrobiol J, 1995, 31: 55-65

6 Traut W, Winking H. Meiotic chromosomes and stages of sex chromosome evolution in fish: Zebrafish, platyfish and guppy. Chromosome Res, 2001, 9: 659-672

7 Artieri C G, Mitchell L A, $\mathrm{Ng} \mathrm{S} \mathrm{H}$, et al. Identification of the sex-determining locus of Atlantic salmon (Salmo salar) on chromosome 2. Cytogenet Genome Res, 2006, 112: 152-159

8 Zhao G, Yu Q X, Zhang W W, et al. The $5 \mathrm{~S}$ rDNA related repetitive sequences in the sex chromosomes of the spiny eel (Mastacembelus aculeatus). Cytogenet Genome Res, 2008, 121: 143-148

9 Lee B Y, Kocher T D. Exclusion of Wilms tumour (WT1b) and ovarian cytochrome P450 aromatase (CYP19A1) as candidates for sex determination genes in Nile tilapia (Oreochromis niloticus). Anim Genet, 2007, 38: 85-86

10 von Hofsten J, Larsson A, Olsson P E. Novel steroidogenic factor-1 homolog $(f f 1 d)$ is coexpressed with anti-Mullerian hormone $(A M H)$ in zebrafish. Dev Dyn, 2005, 233: 595-604

11 von Hofsten J, Olsson P E. Zebrafish sex determination and differentiation: Involvement of FTZ-F1 genes. Reprod Biol Endocrinol, 2005, 3: 63

12 Nakamoto M, Wang D S, Suzuki A, et al. Dax1 suppresses
P450arom expression in medaka ovarian follicles. Mol Reprod Dev, 2007, 74: 1239-1246

13 Rogriguez-Mari A, Yan Y L, Bremiller R A, et al. Characterization and expression pattern of zebrafish Anti-Mullerian hormone (Amh) relative to sox $9 a$, sox $9 b$, and cyp19ala, during gonad development. Gene Expr Patterns, 2005, 5: 655-667

14 Sawyer S J, Gerstner K A, Callard G V. Real-time PCR analysis of cytochrome $\mathrm{P} 450$ aromatase expression in zebrafish: Gene specific tissue distribution, sex differences, developmental programming, and estrogen regulation. Gen Comp Endocrinol, 2006, 147: 108-117

15 Tang B, Hu W, Hao J, et al. Developmental expression of steroidogenic factor-1, cyp19a1a and cyp19a1b from common carp (Cyprinus carpio). Gen Comp Endocrinol, 2010, 167: 408-416

16 Guiguen Y, Fostier A, Piferrer F, et al. Ovarian aromatase and estrogens: A pivotal role for gonadal sex differentiation and sex change in fish. Gen Comp Endocrinol, 2010, 165: 352-366

17 Wang D S, Kobayashi T, Zhou L Y. Foxl2 up-regulates aromatase gene transcription in a female-specific manner by binding to the promoter as well as interacting with ad4 binding protein/steroidogenic factor 1. Mol Endocrinol, 2007, 21: 712-725

18 Vizziano D, Randuineau G, Baron D, et al. Characterization of early molecular sex differentiation in rainbow trout, Oncorhynchus mykiss. Dev Dyn, 2007, 236: 2198-2206

19 Cao M X, Duan J D, Cheng N N, et al. Sexually dimorphic and ontogenetic expression of dmrt1, cyp19ala and cyp19a1b in Gobiocypris rarus. Comp Biochem Physiol A Mol Integr Physiol, 2012, 162: 303-309

20 Matsuda M, Nagahama Y, Shinomiya A, et al. $D M Y$ is a Y-specific DM-domain gene required for male development in the medaka fish. Nature, 2002, 417: 559-563

21 Nanda I, Kondo M, Hornung U, et al. A duplicated copy of DMRT1 in the sex-determining region of the Y chromosome of the medaka, Oryzias latipes. Proc Natl Acad Sci USA, 2002, 99: 11778-11783

22 Hattori R S, Murai Y, Oura M, et al. A Y-linked anti-Mullerian hormone duplication takes over a critical role in sex determination. Proc Natl Acad Sci USA, 2012, 109: 2955-2959

23 Li J, Phillips R B, Harwood A S, et al. Identification of the sex chromosomes of brown trout (Salmo trutta) and their comparison with the corresponding chromosomes in Atlantic salmon (Salmo salar) and rainbow trout (Oncorhynchus mykiss). Cytogenet Genome Res, 2011, 133: 25-33

24 Vandeputte M, Dupont-Nivet M, Chavanne H, et al. A polygenic hypothesis for sex determination in the European sea bass Dicentrarchus labrax. Genetics, 2007, 176: 1049-1057

25 Bradley K M, Breyer J P, Melville D B, et al. An SNP-based linkage map for zebrafish reveals sex determination loci. G3 (Bethesda), 2011, 1: 3-9

26 Liew W C, Bartfai R, Lim Z, et al. Polygenic sex determination system in zebrafish. PLoS One, 2012, 7: e34397

27 Devlin R H, Nagahama Y. Sex determination and sex differentiation in fish: An overview of genetic, physiological, and environmental influences. Aquaculture, 2002, 208: 191-364

28 Conover D O, Kynard B E. Environmental sex determination: Interaction of temperature and genotype in a fish. Science, 1981, 213: 577-579

29 Hayashi Y, Kobira H, Yamaguchi T, et al. High temperature causes masculinization of genetically female medaka by elevation of cortisol. Mol Reprod Dev, 2010, 77: 679-686

30 Roemer U, Beisenherz W. Environmental determination of sex in Apistogramma (Cichlidae) and two other freshwater fishes (Teleostei). J Fish Biol, 1996, 48: 714-725

31 Conover D O, Daemond S B. Absence of temperature dependent sex determination in northern populations of two cyprinodontid fishes. Can J Zool, 1991, 69: 530-533

32 Yamaguchi T, Yamaguchi S, Hirai T, et al. Follicle-stimulating hormone signaling and Fox12 are involved in transcriptional regulation of aromatase gene during gonadal sex differentiation in Japanese flounder Paralichthys olivaceus. Biochem Biophys Res Commun, 2007, 359: 935-940 
33 Sehgal G K, Saxena P K. Effect of estrone on sex composition, growth and flesh composition in common carp, Cyprinus carpio communis (Linn.). J Aquacult Trop, 1997, 12: 289-295

34 Piferrer F, Baker I J, Donaldson E M. Effects of natural, synthetic, aromatizable, and nonaromatizable androgens in inducing male sex differentiation in genotypic female chinook salmon (Oncorhynchus tshawytscha). Gen Comp Endocrinol, 1993, 91: 59-65

35 Ito K, Mochida K, Fujii K. Molecular cloning of two estrogen receptors expressed in the testis of the Japanese common goby, Acanthogobius flavimanus. Zool Sci, 2007, 24: 986-996

36 Chaves-Pozo E, Liarte S, Vargas-Chacoff L, et al. 17Beta-estradiol triggers postspawning in spermatogenically active gilthead seabream (Sparus aurata L.) males. Biol Reprod, 2007, 76: 142-148

37 Miura T, Higuchi M, Ozaki Y, et al. Progestin is an essential factor for the initiation of the meiosis in spermatogenetic cells of the eel. Proc Natl Acad Sci USA, 2006, 103: 7333-7338

38 Liu X, Su H, Zhu P, et al. Molecular cloning, characterization and expression pattern of androgen receptor in Spinibarbus denticulatus. Gen Comp Endocrinol, 2009, 160: 93-101

39 Quinitio G F, Caberoy N B, Reyes Jr D M. Induction of sex change in female Epinephelus coioides by social control. Isr J Aquacult, 1997, 49: 77-83

40 Bhandari R K, Komuro H, Nakamura S, et al. Gonadal restructuring and correlative steroid hormone profiles during natural sex change in protogynous honeycomb grouper (Epinephelus merra). Zool Sci, 2003, 20: 1399-1404

41 Zhou L, Yao B, Xia W, et al. EST-based identification of genes expressed in the hypothalamus of male orange-spotted grouper (Epinephelus coioides). Aquaculture, 2006, 256: 129-139

42 Alam M A, Kobayashi Y, Horiguchi R, et al. Molecular cloning and quantitative expression of sexually dimorphic markers Dmrt1 and Fox12 during female-to-male sex change in Epinephelus merra. Gen Comp Endocrinol, 2008, 157: 75-85

43 Huang X, Guo Y, Shui Y, et al. Multiple alternative splicing and differential expression of dmrt1 during gonad transformation of the rice field eel. Biol Reprod, 2005, 73: 1017-1024

44 Luo Y S, Hu W, Liu X C, et al. Molecular cloning and mRNA expression pattern of Sox 9 during sex reversal in orange-spotted grouper (Epinephelus coioides). Aquaculture, 2010, 306: 322-328

45 Kokokiris L, Fostier A, Athanassopoulou F, et al. Gonadal changes and blood sex steroids levels during natural sex inversion in the protogynous Mediterranean red porgy, Pagrus pagrus (Teleostei: Sparidae). Gen Comp Endocrinol, 2006, 149: 42-48

46 Chang C F, Lee M F, Chen G L. Estradiol- $17 \beta$ associated with the sex reversal in protandrous black porgy, Acanthopagrus schlegeli. J Exp Zool, 1994, 268: 53-58

47 Li G L, Liu X C, Lin H R. Effects of aromatizable and nonaromatizable androgens on the sex inversion of red-spotted grouper (Epinephelus akaara). Fish Physiol Biochem, 2006, 32: 25-33

48 Kojima Y, Bhandari R K, Kobayashi Y, et al. Sex change of adult initial-phase male wrasse, Halichoeres trimaculatus by estradiol-17 beta treatment. Gen Comp Endocrinol, 2008, 156: 628-632

49 Bhandari R K, Alam M A, Soyano K, et al. Induction of female-tomale sex change in the honeycomb grouper (Epinephelus merra) by 11-ketotestosterone treatments. Zool Sci, 2006, 23: 65-69

50 Li G L, Liu X C, Lin H R. Seasonal changes of serum sex steroids concentration and aromatase activity of gonad and brain in redspotted grouper (Epinephelus akaara). Anim Reprod Sci, 2007, 99: 156-166

51 Wu C J, Chen R D, Ye Y Z, et al. Production of all-female carp and its applications in fish cultivation. Aquaculture, 1990, 85: 327

52 Liu H Q, Cui S Q, Hou C C, et al. YY supermale generated gynogenetically from XY female in Pelteobagrus fulvidraco (Richardson) (in Chinese). Acta Hydrobiol Sin, 2007, 31: 718-725

53 Liu Z, Wu F, Jiao B, et al. Molecular cloning of doublesex and mab-3-related transcription factor 1 , forkhead transcription factor gene 2, and two types of cytochrome P450 aromatase in Southern catfish and their possible roles in sex differentiation. J Endocrinol, 2007, 194: 223-241
54 Wang D S, Zhou L Y, Kobayashi T, et al. Doublesex- and Mab-3related transcription factor-1 repression of aromatase transcription, a possible mechanism favoring the male pathway in tilapia. Endocrinology, 2010, 151: 1331-1340

55 Rodriguez-Mari A, Canestro C, Bremiller R A, et al. Sex reversal in zebrafish fancl mutants is caused by Tp53-mediated germ cell apoptosis. PLoS Genet, 2010, 6: e1001034

56 Slanchev K, Stebler J, de la Cueva-Mendez G, et al. Development without germ cells: The role of the germ line in zebrafish sex differentiation. Proc Natl Acad Sci USA, 2005, 102: 4074-4079

57 Kurokawa H, Saito D, Nakamura S, et al. Germ cells are essential for sexual dimorphism in the medaka gonad. Proc Natl Acad Sci USA, 2007, 104: 16958-16963

58 Li W S, Lin H R. The endocrine regulation network of growth hormone synthesis and secretion in fish: Emphasis on the signal integration in somatotropes. Sci China Life Sci, 2010, 53: 462-470

$59 \mathrm{Hu}$ W, Wang Y P, Zhu Z Y. Progress in the evaluation of transgenic fish for possible ecological risk and its containment strategies. Sci China Life Sci, 2007, 50: 573-579

$60 \mathrm{Hu} \mathrm{W}$, Zhu Z Y. Integration mechanisms of transgenes and population fitness of GH transgenic fish. Sci China Life Sci, 2010, 53: 401-408

61 Xu H Y, Li M Y, Gui J F, et al. Fish germ cells. Sci China Life Sci, 2010, 53: 435-446

62 Olsen L C, Aasland R, Fjose A. A vasa-like gene in zebrafish identifies putative primordial germ cells. Mech Dev, 1997, 66: 95-105

63 Kawakami Y, Saito T, Fujimoto T, et al. Visualization and motility of primordial germ cells using green fluorescent protein fused to 3'UTR of common carp nanos-related gene. Aquaculture, 2011, 317: 245-250

64 Raz E, Hopkins N. Primordial germ-cell development in zebrafish. Results Probl Cell Differ, 2002, 40: 166-179

65 Cao M X, Yang Y H, Xu H Y, et al. Germ cell specific expression of Vasa in rare minnow, Gobiocypris rarus. Comp Biochem Physiol A Mol Integr Physiol, 2012, 162: 163-170

66 Shinomiya A, Tanaka M, Kobayashi T, et al. The vasa-like gene, olvas, identifies the migration path of primordial germ cells during embryonic body formation stage in the medaka, Oryzias latipes. Dev Growth Differ, 2000, 42: 317-326

67 Blaser H, Eisenbeiss S, Neumann M, et al. Transition from nonmotile behaviour to directed migration during early PGC development in zebrafish. J Cell Sci, 2005, 118: 4027-4038

68 Raz E, Reichman-Fried M. Attraction rules: Germ cell migration in zebrafish. Curr Opin Genet Dev, 2006, 16: 355-359

69 Boldajipour B, Mahabaleshwar H, Kardash E, et al. Control of chemokine-guided cell migration by ligand sequestration. Cell, 2008, 132: 463-473

70 Herpin A, Fischer P, Liedtke D, et al. Sequential SDF1a and b-induced mobility guides medaka PGC migration. Dev Biol, 2008, 320: 319-327

71 Kunwar P S, Siekhaus D E, Lehmann R. In vivo migration: A germ cell perspective. Annu Rev Cell Dev Biol, 2006, 22: 237-265

72 Herpin A, Schindler D, Kraiss A, et al. Inhibition of primordial germ cell proliferation by the medaka male determining gene Dmrt1bY. BMC Dev Biol, 2007, 7: 99

73 Shiraishi E, Yoshinaga N, Miura T, et al. Mullerian inhibiting substance is required for germ cell proliferation during early gonadal differentiation in medaka (Oryzias latipes). Endocrinology, 2008, 149: 1813-1819

74 Houwing S, Kamminga L M, Berezikov E, et al. A role for Piwi and piRNAs in germ cell maintenance and transposon silencing in Zebrafish. Cell, 2007, 129: 69-82

75 Schulz R W, de França L R, Lareyre J J, et al. Spermatogenesis in fish. Gen Comp Endocrinol, 2010, 165: 390-411

76 Lubzens E, Young G, Bobe J, et al. Oogenesis in teleosts: How fish eggs are formed. Gen Comp Endocrinol, 2010, 165: 367-389

77 Zohar Y, Munoz-Cueto J A, Elizur A, et al. Neuroendocrinology of reproduction in teleost fish. Gen Comp Endocrinol, 2010, 165: 438-455 
78 de Roux N, Genin E, Carel J C, et al. Hypogonadotropic hypogonadism due to loss of function of the KiSS1-derived peptide receptor GPR54. Proc Natl Acad Sci USA, 2003, 100: 10972-10976

79 Tena-Sempere M, Felip A, Gomez A, et al. Comparative insights of the kisspeptin/kisspeptin receptor system: Lessons from non-mammalian vertebrates. Gen Comp Endocrinol, 2012, 175: 234-243

80 Parhar I S, Ogawa S, Sakuma Y. Laser-captured single digoxigeninlabeled neurons of gonadotropin-releasing hormone types reveal a novel $\mathrm{G}$ protein-coupled receptor (Gpr54) during maturation in cichlid fish. Endocrinology, 2004, 145: 3613-3618

81 Kitahashi T, Ogawa S, Parhar I. Cloning and expression of kiss 2 in the zebrafish and medaka. Endocrinology, 2009, 150: 821-831

82 Li S, Zhang Y, Liu Y, et al. Structural and functional multiplicity of the kisspeptin/GPR54 system in goldfish (Carassius auratus). J Endocrinol, 2009, 201: 407-418

83 Pasquier J, Lafont A G, Leprince J, et al. First evidence for a direct inhibitory effect of kisspeptins on LH expression in the eel, Anguilla anguilla. Gen Comp Endocrinol, 2011, 173: 216-225

84 Tsutsui K, Bentley G E, Ubuka T, et al. The general and comparative biology of gonadotropin-inhibitory hormone (GnIH). Gen Comp Endocrinol, 2007, 153: 365-370

85 Zhang Y, Li S, Liu Y, et al. Structural diversity of the gnih/gnih receptor system in teleost: Its involvement in early development and the negative control of LH release. Peptides, 2010, 31: 1034-1043

86 Moussavi M, Wlasichuk M, Chang J P, et al. Seasonal effect of $\mathrm{GnIH}$ on gonadotrope functions in the pituitary of goldfish. Mol Cell Endocrinol, 2012, 350: 53-60

87 Trudeau V L. Neuroendocrine regulation of gonadotrophin II release and gonadal growth in the goldfish, Carassius auratus. Rev Reprod, 1997, 2: 55-68

88 Popesku J T, Martyniuk C J, Mennigen J, et al. The goldfish (Carassius auratus) as a model for neuroendocrine signaling. Mol Cell Endocrinol, 2008, 293: 43-56

89 Xu J, Huang W, Zhong C R, et al. Defining global gene expression changes of the hypothalamic-pituitary-gonadal axis in female sGnRH-antisense transgenic common carp (Cyprinus carpio). PLoS One, 2011, 6: e21057

90 Uzbekova S, Chyb J, Ferriere F, et al. Transgenic rainbow trout expressed sGnRH-antisense RNA under the control of sGnRH promoter of Atlantic salmon. J Mol Endocrinol, 2000, 25: 337-350

91 Maclean N, Hwang G, Molina A, et al. Reversibly-sterile fish via transgenesis. ISB News Report, 2003, 1-3

$92 \mathrm{Hu} \mathrm{W}$, Li S F, Tang B, et al. Antisense for gonadotropin-releasing hormone reduces gonadotropin synthesis and gonadal development in transgenic common carp (Cyprinus carpio). Aquaculture, 2007, 271: 498-506

93 Weidinger G., Stebler J, Slanchev K, et al. dead end, a novel vertebrate germ plasm component, is required for zebrafish primordial germ cell migration and survival. Curr Biol, 2003, 13: 1429-1434

94 Koprunner M, Thisse C, Thisse B, et al. A zebrafish nanos-related gene is essential for the development of primordial germ cells. Genes Dev, 2001, 15: 2877-2885

95 Ramasamy S, Wang H, Quach H N, et al. Zebrafish Staufen1 and Staufen 2 are required for the survival and migration of primordial germ cells. Dev Biol, 2006, 292: 393-406

96 Hsu C C, Hou M F, Hong J R, et al. Inducible male infertility by targeted cell ablation in zebrafish testis. Mar Biotechnol, 2010, 12: 466-478

97 Hu S Y, Lin P Y, Liao C H, et al. Nitroreductase-mediated gonadal dysgenesis for infertility control of genetically modified zebrafish. Mar Biotechnol, 2010, 12: 569-578

98 Wakamatsu Y, Ju B, Pristyaznhyuk I, et al. Fertile and diploid nuclear transplants derived from embryonic cells of a small laboratory fish, medaka (Oryzias latipes). Proc Natl Acad Sci USA, 2001, 98:
1071-1076

99 Hu W, Wang Y P, Chen S P, et al. Nuclear transplantation in different strains of zebrafish. Chin Sci Bull, 2002, 47: 1277-1280

100 Lee K Y, Huang H, Ju B, et al. Cloned zebrafish by nuclear transfer from long-term-cultured cells. Nat Biotechnol, 2002, 20: 795-799

101 Liu T M, Liu L, Wei Q W, et al. Sperm nuclear transfer and transgenic production in the fish medaka. Int J Biol Sci, 2011, 7: 469-475

102 Luo D J, Hu W, Chen S P, et al. Identification of differentially expressed genes between cloned and zygote-developing zebrafish (Danio rerio) embryos at the dome stage using suppression subtractive hybridization. Biol Reprod, 2009, 80: 674-684

103 Luo D J, Hu W, Chen S P, et al. Critical developmental stages for the efficiency of somatic cell nuclear transfer in zebrafish. Int J Biol Sci, 2011, 7: 476-486

104 Takeuchi Y, Yoshizaki G, Takeuchi T. Generation of live fry from intraperitoneally transplanted primordial germ cells in rainbow trout. Biol Reprod, 2003, 69: 1142-1149

105 Saito T, Goto-Kazeto R, Arai K, et al. Xenogenesis in teleost fish through generation of germ-line chimeras by single primordial germ cell transplantation. Biol Reprod, 2008, 78: 159-166

106 Saito T, Goto-Kazeto R, Fujimoto T, et al. Inter-species transplantation and migration of primordial germ cells in cyprinid fish. Int $\mathrm{J}$ Dev Biol, 2010, 54: 1481-1486

107 Nobrega R H, Greebe C D, van de Kant H, et al. Spermatogonial stem cell niche and spermatogonial stem cell transplantation in zebrafish. PLoS One, 2010, 5: e12808

108 Majhi S K, Hattori R S, Yokota M, et al. Germ cell transplantation using sexually competent fish: An approach for rapid propagation of endangered and valuable germlines. PLoS One, 2009, 4: e6132

109 Okutsu T, Shikina S, Kanno M, et al. Production of trout offspring from triploid salmon parents. Science, 2007, 317: 1517

110 Lacerda S M, Batlouni S R, Costa G M. A new and fast technique to generate offspring after germ cells transplantation in adult fish: The Nile tilapia (Oreochromis niloticus) model. PLoS One, 2010, 5: e10740

111 Hong Y H, Winkler C, Schartl M. Pluripotency and differentiation of embryonic stem cell lines from the medakafish (Oryzias latipes). Mech Dev, 1996, 60: 33-44

112 Yi M S, Hong N, Li Z D, et al. Medaka fish stem cells and their applications. Sci China Life Sci, 2010, 53: 426-434

113 Chen S L, Sha Z X, Ye H Q, et al. Pluripotency and chimera competence of an embryonic stem cell line from the sea perch (Lateolabrax japonicus). Mar Biotechnol, 2007, 9: 82-91

114 Fan L C, Collodi P. Zebrafish embryonic stem cells. Methods Enzymol, 2006, 418: 64-77

115 Yi M S, Hong N, Hong Y H. Generation of medaka fish haploid embryonic stem cells. Science, 2009, 326: 430-433

116 Hong Y H, Liu T M, Zhao H B, et al. Establishment of a normal medakafish spermatogonial cell line capable of sperm production in vitro. Proc Natl Acad Sci USA, 2004, 101: 8011-8016

117 Sakai N. In vitro male germ cell cultures of zebrafish. Methods, 2006, 39: 239-245

118 Fan L C, Moon J, Wong T T, et al. Zebrafish primordial germ cell cultures derived from vasa: RFP transgenic embryos. Stem Cells Dev, 2008, 17: 585-597

119 Shikina S, Yoshizaki G. Improved in vitro culture conditions to enhance the survival, mitotic activity, and transplantability of rainbow trout type A spermatogonia. Biol Reprod, 2010, 83: 268-276

120 Panda R P, Barman H K, Mohapatra C. Isolation of enriched carp spermatogonial stem cells from Labeo rohita testis for in vitro propagation. Theriogenology, 2011, 76: 241-251

121 Nakamura S, Kobayashi K, Nishimura T, et al. Identification of germline stem cells in the ovary of the teleost medaka. Science, 2010, 328: 1561-1563

Open Access This article is distributed under the terms of the Creative Commons Attribution License which permits any use, distribution, and reproduction in any medium, provided the original author(s) and source are credited. 